\title{
REGISTROS PAROQUIAIS DA FREGUESIA DE BENFICA EM BELÉM: ANÁLISE DA ORIGEM FUNDIÁRIA
}

\author{
Natalia Altieri Santos de Oliveira ${ }^{1}$ \\ Luly Rodrigues da Cunha Fischer ${ }^{2}$
}

\section{RESUMO}

Apresenta um estudo acerca da origem fundiária da cidade de Belém. Justifica a pesquisa pela importância do conhecimento da origem fundiária de Belém. Apresenta o sistema sesmarial, o período da posse, bem como as disposições da lei de terras e do seu decreto, além de uma análise do registro paroquial, e a aplicação da lei de terras nos perímetros urbanos. São apresentados dados quantitativos e qualitativos. Conclui que não foi possível identificar qual era a origem fundiária da cidade nem a sua possível atual localização, em razão da imprecisão dos dados declarados.

Palavras-chave: História do Direito; Registro Paroquial; Belém; Lei de Terras; Benfica.

\section{PARISH RECORDS OF THE PARISH OF BENFICA IN BELÉM: ANALYSIS OF THE FOUNDRY ORIGIN}

\begin{abstract}
Presents a study about the land origin of the city of Belém. It justifies the research by the importance of knowledge of the land of Belém. It presents the sesmarial system, the period of possession, as well as the provisions of the land law and its decree, besides An analysis of the parish register, and the application of the land law in urban perimeters. Quantitative and qualitative data are presented. It concludes that it was not possible to identify the land origin of the city or its possible current location, due to the imprecision of the declared data.
\end{abstract}

Keywords: History of Law; Parish Registration; Belém; Land Law; Benfica.

\section{INTRODUÇÃO}

A análise dos registros paroquiais que foram consignados em todo o período de vigência da Lei de Terras e do Decreto $n^{\circ} 1.318$ de 1850 se faz importante em razão dos mesmos serem fonte para se conhecer a origem da organização fundiária dos mais diversos municípios brasileiros. Partindo desta afirmação, a escolha pelo exame dos registros

\footnotetext{
${ }^{1}$ Mestranda do Programa de Pós Graduação em Direito na Universidade Federal do Pará. Bolsista CAPES. Email: nataliaaaltieri@gmail.com

${ }^{2}$ Luly Rodrigues da Cunha Fischer - Doutora em Direito da UFPA/Université Paris XIII. Professora de Direito da Universidade Federal do Pará - (UFPA). Email: lulyfischer@yahoo.com
} 
paroquiais existentes da Freguesia de Benfica foi baseada em pesquisa feita nos livros de todas as Freguesias que possuem declarações de partes de Belém.

O problema inicial a ser respondido com o presente trabalho era qual seria a origem fundiária da cidade de Belém relatada por meio das declarações formuladas pelos seus próprios habitantes à época da manutenção do livro da Freguesia de Benfica, e se seria possível identificar a atual correspondência destes registros na atual configuração urbana da cidade.

A hipótese inicialmente formulada para responder tal problema e que serão provadas ou não são relativas ao fato de que a origem fundiária de Belém era baseada, em grande parte, de propriedades oriundas de meras posses, ou seja, que grande parte da estrutura da cidade não era feita de áreas devidamente tituladas.

Nesse sentido, o objetivo principal deste trabalho é o estudo da origem fundiária da cidade, tendo como objetivos específicos a identificação dos registros paroquiais da Freguesia de Benfica e com base nestes, verificar quais foram os regimes jurídicos de propriedade que justificaram os mesmos, a fim de analisar como se caracterizava inicialmente a questão fundiária no município de Belém.

Para tanto, serão estudados também o contexto de regime sesmarial, da época do império da posse, efeitos da lei de terras e seu decreto regulamentador, a origem dos municípios, em especial de Belém, e claro, a aplicabilidade da lei de terras nos perímetros urbanos.

A metodologia utilizada no presente trabalho iniciou-se com a pesquisa de campo do livro da Freguesia ora estudada, com a consequente sistematização e análise dos dados colhidos com base no método interpretativo histórico, bem como com a revisão bibliográfica sobre a temática.

A exposição dos resultados da pesquisa foi organizada em três partes. Primeiramente, será apresentado o contexto fundiário e normativo em que foi editada a lei $\mathrm{n}^{\circ} 601$ de 1850 , com a apresentação do sistema sesmarial, o período da posse, bem como as disposições da lei de terras e do seu decreto regulamentador, além de uma breve análise do registro paroquial. Na segunda parte será exposta a aplicação da lei de terras nos perímetros urbanos. Por fim, serão apresentados os dados referentes à aplicação da lei de terras no município de Belém por meio da análise realizada dos registros paroquiais de Benfica. 


\section{SISTEMATIZAÇÃO FUNDIÁRIA NO ANTIGO REGIME E A LEI DE TERRAS DE 1850: ANÁLISE DO INSTITUTO DO REGISTRO PAROQUIAL}

A origem da estrutura agrária nacional encontra-se no Direito Português, haja vista que não houve a criação inicial de uma legislação própria para a colônia (BENATTI, 2003). Com a ocupação portuguesa em 1500, todas as terras brasileiras passaram a pertencer a Portugal, cabendo ao Rei a permissão ou não do acesso a estas (TRECCANI, 2009).

O histórico dos instrumentos legais de organização das terras inicia-se com as Ordenações Portuguesas (COSTA et al, 2011), mas foram as Ordenações Filipinas de 1603 (ALMEIDA, 1870) as normas que de fato disciplinaram a primeira forma de distribuição de terras em nosso ordenamento nacional, gerando problemas fundiários que repercutem na contemporaneidade, decorrentes da imprecisão de suas delimitações (BENATTI, 2003).

Eram concessões gratuitas para homens de muitas posses, mas não eram feitas de forma incondicionada, na medida em que aqueles que recebiam as porções de terras tinham como obrigação a construção de torres ou fortalezas para a defesa da terra, bem como o dever de levar pessoas para promover o povoamento das novas terras, sob pena de ter a terra devolvida ao patrimônio público real, o que mais tarde seria conhecido como terras devolutas (ROCHA et al, 2010).

Durante o período em que o sistema sesmarial esteve em vigor no Brasil, diversas leis, decretos, cartas régias, alvarás, provisões, resoluções e avisos foram editados, o que culminou em uma confusão legislativa e descontinuada (NOZOE, 2006). As cartas de sesmarias não significavam a instituição de propriedade, mas sim o direito de uso das terras que eram concedidas pelo rei português (ROCHA et al, 2010). Neste sentido, em termos jurídicos a propriedade privada moderna apenas passou a existir de fato com a promulgação da Lei de Terras e sua previsão do acesso por meio de compra e venda. (CHRISTILLINO, 2006).

A estrutura social e econômica existente na época do período colonial possibilitou o surgimento também da propriedade senhorial, que é descrita por Benatti (2003) como uma forma de apossamento primário da terra sem transferência oficial do bem público para o patrimônio particular, legitimando-se pelo benefício da terra. Esse sistema resultou em uma contradição com algumas das diretrizes do sistema sesmarial, na medida em que, ao contrário deste último que era codificado, o sistema senhorial era proveniente do direito costumeiro brasileiro, possibilitando a construção de uma concepção jurídica favorável a este tipo de 
apropriação privada, fazendo com que ocupação como uma das formas de acesso à terra fosse consolidada.

Nesse mesmo período, o regime sesmarial caiu em desuso em Portugal com a revogação das Ordenações Filipinas (NOZOE, 2006). No Brasil, a declínio do regime sesmarial se deu em razão do fato deste não ter sido adaptado ao ser aplicado no Brasil, fazendo com que o objetivo inicial, que era transformar o Brasil numa colônia com ocupação produtiva, se perdesse, pois o que encontrava eram grandes porções de terras improdutivas (TRECCANI, 2011).

Ante a ausência de um regime único, bem como os abusos que este fato deu margem, foi editada a Resolução ${ }^{\circ} 76$, de 17 de julho de 1822, que suspendeu a concessão de novas sesmarias até que fosse convocada Assembleia Geral Constituinte, determinando ainda que aqueles que estivessem na posse deveriam permanecer na terra (NOZOE, 2006), fazendo com que, a partir de então o Brasil não dispusesse de norma que regulamentasse devidamente o acesso a terra, coexistindo diferentes formas de apropriação da terra, dividindo-se entre as propriedades que eram oriundas das sesmarias confirmadas; as posses ilegítimas que se eram as sesmarias caídas em comisso em razão do descumprimento de alguma cláusula; e posses estabelecidas em terras públicas sem qualquer alvará do poder público (ROCHA et al, 2010).

Cumpre destacar, que as posses ilegítimas se expandiram em demasia, motivo pelo qual tal período passou a ser conhecido como período áureo da posse (MATTOS NETO, 2009), que deu histórico deu-se pouco antes da Independência do Brasil, fazendo com que durante 28 anos o Brasil ficasse sem uma regulamentação de acesso a terra, facilitando a dissipação da posse sem autorização ou fiscalização oficial do governo (BENATTI, 2003). Neste período, o posseiro ocupou não apenas as sesmarias abandonadas ou não cultivadas, mas também alguns latifúndios pouco explorados (ARAÚJO, 2010).

Foi com a promulgação da Lei $\mathrm{n}^{\circ} 514$ de 1848, mais precisamente o seu artigo 16, que se pode falar na primeira tentativa de se promover a colonização do espaço brasileiro neste período de caos normativo. A lei regulou os mais variados assuntos de organização administrativa, estabelecendo o supracitado artigo que a União doaria porções de terra às Províncias com a finalidade de colonizar seus respectivos territórios, caso os colonos não cumprissem com as condições impostas no prazo de cinco anos.

Assim, houve a manutenção do regime da posse, que havia nascido justamente com o regime senhorial, tendo como uma das principais consequências o aumento do 
desconhecimento por parte do governo português de quais eram as terras que ainda eram de seu domínio legal e quais faziam parte do domínio particular.

Na análise de Porto (1979) a edição da Lei 601/1850 decorre da necessidade da sociedade brasileira de um marco legal que regulasse o acesso a terra. Nesse sentido, a promulgação de uma lei brasileira que regesse não apenas o acesso à terra, mas também organizasse quais eram as propriedades que ainda estavam sob o domínio público e quais haviam passado para o domínio particular.

A lei $n^{\circ} 601$ de 18 de setembro de 1850 foi promulgada com o objetivo de regular as terras devolutas do Império, bem como as terras que eram possuídas por meio de título de sesmaria que não haviam preenchido todos os requisitos $\left(\operatorname{art.} 1^{\circ}\right)$. A finalidade principal da lei era por fim ao caos que imperava até então em razão da ausência de normais que regulassem o acesso a terra, passando a distinguir o que era de propriedade privada e o que era de propriedade pública (BENATTI, 2003). Foram criadas quatro soluções para que houvesse o reconhecimento da propriedade que até então se encontrava irregular: a carta de sesmaria poderia ser revalidada (ainda que não tivesse preenchido as demais exigências legais anteriores para a comprovação do cultivo da terra); a legitimação das posses; as compras das terras devolutas; e por meio de doação (sendo este último aplicável apenas nas faixas de fronteira) (TRECCANI, 2009).

No que diz respeito às sesmarias confirmadas, a Lei de terras tinha como objetivo criar um mecanismo que consolidasse de vez a propriedade que era oriunda das sesmarias já confirmadas, afastando de vez a possibilidade de as mesmas perderem o caráter de propriedade em razão de revogação vinda por Parte do reino de Portugal. A solução encontrada foi a garantia do domínio das mesmas sem que para isso precisasse ocorrer a revalidação das mesmas.

Com relação às sesmarias concedidas, o problema inicial era a sua revalidação e legitimação das posses. Faz-se mister salientar que "muitas sesmarias concedidas antes de 1822 haviam caído em comisso e que todas as propriedades ocupadas após aquela data eram posses não legitimadas" (CARVALHO, 1981). Sendo assim, fazia-se imprescindível que as terras (propriedades ou meras posses) fossem medidas e devidamente tituladas, sob pena de serem consideradas como terras devolutas.

Aqueles que, a partir da promulgação de tal lei se apossassem das terras públicas ou alheias seriam despejados das mesmas e não teriam direito a qualquer indenização oriunda das benfeitorias que porventura tivessem feito. Tal situação assim se explicava em virtude de tal 
ocupação irregular passar a ser considerada como um crime, limitando, assim, o acesso à terra a quem apenas dispusesse de capital suficiente para comprá-las, excluindo aquele que apenas detivesse de sua força laboral.

Contudo, ainda que as doações que foram feitas anteriormente à promulgação da referida lei - por meio da lei $n^{o} 514$ de 1848, no seu artigo 16, supracitado - não fossem nulas, apenas ficou coibida a cessão de novas terras de forma gratuita fora das exceções previstas em lei. Essas doações diziam respeito às porções de terras que o Império concedeu a cada Província com o objetivo de promover a colonização, sendo vedado aos colonos que transferissem as terras enquanto que as mesmas permanecessem aproveitadas. Para que a validade das doações permanecesse, era de grande importância que as Províncias informassem ao governo central quais eram as porções que seriam aproveitadas com o fim de demarcá-las.

Neste sentido, é notável que as concessões previstas na lei 514 de 1858 tinham por finalidade exclusiva a colonização, e em nenhum momento se falava na possibilidade de adquirir a propriedade, como a lei de terras previa. Logo, ainda que se tratassem de concessões, cada uma tinha um objeto diferente, fazendo com que a sua coexistência não se tornasse um grande empecilho. A coexistência desses dois regimes de concessão de terras foi confirmada por meio do Aviso no 119 de 24 de março de 1851 (apud FREITAS, 1882).

Contudo, ainda que as doações fossem apenas aquelas feitas nas exceções legais, fazse mister salientar que, de acordo com o Aviso no 225 de 1872, ainda era possível existir outras doações gratuitas, mas seriam feitas pelo poder legislativo (LACERDA, 1960). Outrossim, uma das grandes inovações estava justamente logo no primeiro artigo, qual seja a proibição de aquisição de terras por meio diverso à compra, salvo casos excepcionais previstos na própria lei. Cumpre destacar ainda que, posteriormente, por meio da lei $\mathrm{n}^{\mathrm{o}} 628 \mathrm{de}$ 17 de setembro de 1851 , ficou defeso a disposição de arrendamento nas terras que eram consideradas como devolutas.

Entretanto, foi apenas em 1854 que a Lei de Terras foi devidamente regulamentada, por meio do decreto $\mathrm{n}^{\circ} 1.318$, que tinha como objetivo executar de fato a de Lei $\mathrm{n}^{\circ} 601 / 1850$, em razão das mais diversas autorizações que foram concedidas com fundamento na lei de terras (FREITAS, 1882).

O registro Paroquial, por sua vez, estava previsto no artigo 13 da Lei de Terras e no artigo 93 do decreto 1.318, e foi instituído com o objetivo de se conhecer quantas terras já haviam sido ocupadas, tendo como base as declarações daqueles que se diziam ser seus 
possuidores. Era um instrumento de decisão acerca do domínio sobre as terras em cada localidade, o que gerou diversas tensões (FERREIRA, 2012). A organização dar-se-ia por meio de freguesias e as declarações seriam registradas pelos párocos responsáveis nos exatos termos ditos pelas pessoas, sem que para tanto necessitasse de documentos para comprovar as alegações que eram feitas, tornando, assim, com que o Registro Paroquial fosse alvo fácil de diversas críticas quanto à sua confiabilidade. Uma das críticas enfrentas pelo instituto foi a de que este não seria suficiente para que o Governo conseguisse discriminar as terras públicas e privadas ou de até mesmo conseguir impor que houvesse o registro das terras (MOTTA, 2005).

Apesar disso, o Registro Paroquial foi a primeira tentativa de se criar um cadastro de terras por meio do seu recenseamento, na medida em que todos eram obrigados a registrar o que possuíam, ainda que fossem meros posseiros (artigo 91 do Decreto $\mathrm{n}^{\mathrm{o}} 1.318$ de 1854) ou até mesmo foreiros (ROCHA et al, 2010). Entretanto, os arrendatários estavam excluídos desta obrigatoriedade (FREITAS, 1882). Foi possível notar que o assento no registro estava intrinsecamente ligado ao animus de permanecer no local, ainda que não possuísse qualquer tipo de título (FREITAS, 1822).

Contudo, apesar da finalidade inicial do registro paroquial estar ligado ao conhecimento estatístico das terras, os mesmos são uma rica fonte para se conhecer as situações dos imóveis, quais e quantos eram os seus confinantes, e a sua localização, podemse construir até uma reprodução de onde seriam os locais mais habitados das cidades, à época das declarações (MARCÍLIO, 2004).

É possível notar que o registro paroquial apesar de todas as críticas que enfrentou, principalmente no que tange a não ser um documento hábil para comprovar a posse ou tampouco a propriedade, é um instituto de extrema importância para entender como se construiu a estrutura fundiária de uma determinada cidade. No presente trabalho, busca-se compreender como foi a origem da ocupação territorial urbana na cidade de Belém com base no estudo das declarações registradas na Freguesia de Sant'Anna da Campina nos anos de 1854 a 1858, ano em que o livro foi finalizado, com 83 registros.

O efeitos práticos da lei de terras e do Decreto $\mathrm{n}^{\circ} 1.318$ foram diversos, sendo importante salientar que a Lei de terras fez efetivamente foi limitar o acesso à terra dos exescravos e dos imigrantes recém chegados a partir de então (ARAÚJO, TÁRREGA, 2011), não tendo cumprido a finalidade inicial que em tese era a de diminuir as grandes propriedades, ao passo que apenas aqueles que detinham dinheiro eram quem de fato 
compravam as terras, além de sempre alegarem que estavam ocupando a terra tempo suficiente para demandar a aplicação do instituto do usucapião (BENATTI, 2003).

Em algumas cidades, como Belém (conforme destaca a lei provincial) e Petrópolis (AMBROZIO, 2012), por exemplo, a lei de terras foi aplicada nos perímetros urbanos por meio do regime de enfiteuse, escolha essa que poderia ser justificada em razão desse regime render crédito para as Câmaras Municipais, que eram uma das principais detentoras de patrimônio. Nesse sentido, se faz importante analisar melhor este instituto, o que no presente trabalhos será feito por meio do estudo dos registros paroquiais de Benfica.

\section{APLICAÇÃO DA LEI DE TERRAS PARA O RECONHECIMENTO DA POSSE DE NÚCLEOS URBANOS}

A ingerência do governo na organização/estruturação urbana das cidades no Brasil Português não se dava por meio de normas próprias, como ocorreram nas colônias espanholas, mas sim por meio de agentes do reino que se destacaram na criação e implementação dos projetos de engenharia de fortes, que serviam principalmente para proteger as terras ali povoadas, tanto que muitos dos centros urbanos foram projetados e cresceram a partir da construção de fortes, Igrejas e praças (ARAÚJO, 1998).

A influência da Igreja Católica na organização urbana é datada desde o nascimento das primeiras povoações, em que os atos normativos da Igreja eram usados como meios para garantir a posse ou mesmo de conseguir algum lugar para morar, na medida em que para que o reconhecimento de um arraial (o embrião de muitas cidades) por parte do Estado iniciava-se através da Igreja (MARX, 1991).

Além disso, o prestígio da Igreja no tocante ao processo de urbanização é evidenciado no que diz respeito ao fato do clero ser mantido pelo governo português como se fosse um dos seus agentes reais que tivesse o poder de gerência no novo espaço urbano a ser construído, na medida em que "a mentalidade colonialista dos séculos XVI, XVII e XVIII encontrava-se impregnada de uma visão catequizadora e regeneradora dos territórios conquistados" (ARAÚJO, 1998).

O nascimento dos primeiros esboços do que podemos considerar como centros urbanos se deu por meio de exceções criadas no próprio sistema de terras das sesmarias, na medida em que era de extremamente necessário que as áreas não fossem consideradas como 
improdutivas, e uma porção de terra que possuía uma Igreja (ainda que bem pequena), assim não seria considerada e o possuidor não perderia a sua concessão de sesmaria (MARX, 1991).

Foi com o crescimento dessas Freguesias que as unidades municipais passaram a ter autonomia dentro do Estado, consolidando de vez a influência da Igreja para com o ordenamento territorial urbano, além de demandar cada vez mais que houvesse a delimitação das áreas dos novos municípios nascentes, na medida em que as imprecisões territoriais era problema frequente desde a época das concessões das sesmarias, culminando ainda em abusos de aproveitamento da terra alheia, problema este intensificado posteriormente (MARX, 1991).

A posse então passou a ser considerada como uma característica essencial dos centros urbanos que nasceram na época do Brasil colônia, principalmente quando se levava em consideração o fato de que a posse efetiva da terra ajudava na questão da defesa destas, o que era essencial para o governo português (ARAÚJO, 1998).

Na Amazônia, mais especificamente São Luis e Belém, o contexto histórico que antecedeu o nascimento das referidas cidades é relacionado com às invasões que estas porções de terras sofriam, tanto que o nascimento destas cidades se deu por razões militares, sendo o ponto de partida, novamente, os fortes que eram construídos (ARAÚJO, 1998).

É notável, portanto, a existência de duas origens distintas para os primeiros centros urbanos na Amazônia: o nascimento a partir de um forte, caracterizando as chamadas "cidades-fortalezas", ou o nascimento a partir de pequenos núcleos que foram se formando a partir das igrejas como alternativa para que não houvesse a devolução da porção da terra para o reino português, levando as cidades a um status de símbolo maior da colonização portuguesa (ARAÚJO, 1998), mas sempre com a característica principal de que a terra que nascia as cidades era de controle predominante público, sem que houvesse a constituição verdadeira de porções de domínio privado.

Visando a colonização e exploração do restante do território, muitas foram as expedições realizadas pelos jesuítas (principalmente), fazendo com que rapidamente a extensão da capitania do Grão-Pará se estendesse até a entrada do Amazonas, ocorrendo, na mesma época, diversas doações à particulares (ARAÚJO, 1998). Essas doações em grande parte feitas com o uso do instituto da enfiteuse, que havia sido importada do Direito português sem que houvesse a promulgação de um dispositivo legal que regulasse a localização o a área do terreno que seria aforado, existindo casos, como por exemplo, na cidade de Belém, concessões que foram feitas em momento em que o município assim não poderia proceder em razão de não ter havido ainda a confirmação da doação da sesmaria que fazia composição de 
seu patrimônio. Cumpre destacar ainda que as doações feitas por meio do instituto da enfiteuse estavam circunscritas aos perímetros urbanos que estavam se desenvolvendo; no âmbito rural, as doações eram feitas por meio de sesmarias.

As doações por meio da enfiteuse, tal como as sesmarias, tomaram grandes proporções, tendo até saído do controle do reino português, que tentou estabelecer limites que controlassem tais concessões, na medida em que existiam diversos abusos praticados pelos intermediários que elegiam como recebedores um seleto grupo social, sem que houvesse o uso efetivo de tais terras (ARAÚJO, 1998).

Assim, os centros urbanos já nasciam com problemas no tocante a sua organização fundiária e dominial, tornando-se dúvida a aplicação da lei de terras no âmbito urbano, na medida em que é cristalino que os referidos problemas deveriam ser dirimidos de alguma forma, sendo a lei de terras um dos mecanismos viáveis, como será explicado abaixo, especificamente no que diz respeito a cidade de Belém.

Neste sentido, a primeira dúvida surgida é relativa à aplicação da Lei no 601 de 1850 no âmbito urbano, na medida em que, como estudado até agora, muito se falava na regularização do acesso à terra tendo como um dos pressupostos de cultura efetiva, o que, em tese, se remeteria apenas ao espaço rural, onde comumente há a lavoura.

Como dito acima, as concessões eram em diversos casos feitas com base no instituto da enfiteuse, contudo, muitas eram as situações em que o particular apenas ocupava o terreno sem que houvesse qualquer tipo de permissão daquele que era o real dono da propriedade, elucidando que a ausência de normatização não produzia efeitos exclusivamente na área rural na medida em que a forma que os espaços urbanos nasceram e foram se consolidando, fez com que o problema da regularização também ocorresse nas cidades, pois muitas destas, por exemplo, foram construídas com base em uma só porção de sesmarias já confirmadas (e, portanto, sendo considerada como patrimônio particular), ocorrendo nestes casos, pequenas unidades de posse.

É neste ponto que é notável a influência da lei de terras no âmbito urbano, na medida em que o problema da desordem ocupacional oriunda da ausência de especificação das terras públicas também afetava as cidades, tendo em vista o seu processo de crescimento outrora já descrito (MARX, 1991). Assim, a legitimação destas posses se fazia imprescindível para a regularização destas, sendo tal processo regulado, até então, apenas por meio da lei de terras e o decreto $\mathrm{n}^{\mathrm{o}} 1.318$ de 1854 , na medida em que a Lei $\mathrm{n}^{\circ} 601$ de 1850 denotava a ideia de planejamento territorial, fosse ele urbano ou rural (FRIDMAN; RAMOS, 2012). 
Além disso, cumpre destacar que os patrimônios municipais inicialmente eram formados por meio de concessões solicitadas pelas Câmaras Municipais pelo Governo Português, existindo, posteriormente concessões feitas de cartas de sesmarias e doações particulares, fazendo com que muitos municípios se considerassem possuidores do direito a ocupação de terras nos termos da Lei n 601 de 1850, fazendo suas declarações de posse, com o consequente respeito das respectivas propriedades conquanto a vigência do Decreto 1.318 de 1854 (MUNIZ, 1904).

De acordo ainda com Muniz (1904), apenas os municípios de Ourém, Monte Alegre, Ponta de Pedras, Soure, Portel, Quatipuru, Oeiras, Melgaço, Muaná Itaituba e Cametá no Estado do Pará possuíam a real discriminação de seu patrimônio municipal. Sendo assim, é patente a ausência de dados concretos e totais do patrimônio da cidade de Belém, especialmente quando levado em consideração a existência de doações no período em que a concessão da primeira légua patrimonial ainda não havia sido confirmada.

Neste sentido, tendo em vista que a finalidade da lei de terras era a de legalizar o acesso à terra, a mesma necessidade fazia-se presente nas cidades, uma vez que a existência de propriedades não regularizadas também era algo constante, pois o nascimento e crescimento das mesmas normalmente eram oriundos de uma só grande propriedade que era divida aos demais sem qualquer tipo de transferência formal (MARX, 1991).

Contudo, apesar do artigo 91 do decreto $n^{\circ} 1.318$ de 1854 preceituar que todos os possuidores são obrigados a registrar a suas terras no prazo estipulado, existiam casos, especialmente no tocante à área urbana, que se excetuavam de tal imposição legal. Um exemplo são os terrenos aforados pelas Câmaras Municipais. De acordo com o Aviso n ${ }^{\circ} 17$ de 29 de setembro de 1855, as áreas circunscritas dentro da linha divisória prevista na Circular de 13 de janeiro ${ }^{3}$ do mesmo ano não eram obrigadas a registrar os seus terrenos. Entretanto, caso o fizessem, deveriam descrever as condições que foram feitos os aforamentos (FREITAS, 1882).

Nos perímetros urbanos paraenses, mais especificamente, a aplicação da lei de terras foi regulada pela Lei Provincial no 394 de 25 de outubro de 1861. Na capital, Belém, a lei de terras foi aplicada por meio do artigo 11 da referida lei provincial, que determinada que o patrimônio da câmara municipal que estivessem devolutos (ou seja, sem posseiros), seria objeto de aforamento a quem assim requeresse, dando preferência àqueles que oferecessem melhores condições para edificar e aproveitar o terreno, pagando um foro anual de dez réis

\footnotetext{
${ }^{3}$ Não foi possível encontrar o exato teor do Aviso e da Circular em questão nas publicações das decisões do Império.
} 
por braça quadrada. Além disso, o pagamento de foro representava uma das principais rendas da câmara municipal de Belém (artigo $2^{\circ}, \S^{\circ}$ ).

Outro ponto importante é a cobrança da décima em cima dos prédios urbanos com exceção para aqueles da capital. A décima urbana, por sua vez, foi um imposto instituído no Brasil em 1641 no reinado de D. João IV e era fiscalizado por meio das juntas da décima urbana, que foram criadas por meio do Alvará de 27 de junho de 1858.

Nesse sentido, deixava de ser obrigatório o registro paroquial nas áreas em que a décima urbana era aplicada, pois o registro paroquial tinha finalidade estatística, e o governo já possuía conhecimento das terras que estavam alocadas nesse perímetro, na medida em que eram obrigadas a pagar regularmente o imposto cobrado, qual seja, a décima urbana.

Contudo, o que se verifica é que a lei de terras foi aplicada em diversos municípios paraenses como mecanismo para a discriminação dos patrimônios públicos. Foi o caso de Ourém, Monte Alegre, Ponta de Pedras, Soure, Portel, Quatipuru, Oeiras, Melgaço, Muaná, Itaituba e Cametá, que, por exemplo, tiveram todo o seu patrimônio discriminado e conhecido por meio da aplicação da lei de terras (OLIVEIRA; FISCHER, 2017).

A décima urbana antecede a cobrança de foros, na medida em que antes da Lei de Terras, o imposto urbano obrigatório era justamente a décima urbana, mas não gerava receitas volumosas aos municípios na medida em que era aplicada apenas aos prédios com localização em ruas arruadas e edificadas (AMBROZIO, 2012), o que era uma parte mínima das cidades.

Mesmo com a instituição da Lei de Terras de que o acesso a terra deveria ser mediante compra e venda, o que se nota na realidade urbana é que a prática de concessão de terra pública mediante o instituto da enfiteuse permaneceu por um longo período, na medida em que, como supracitado, gerava receita para os municípios. Esse fato apenas reafirma que as áreas urbanas, de certa maneira, já recebiam um tratamento diferenciado das demais (BRITTO, 2006).

Ademais, a falta de precisão do que necessariamente se considerava como área urbana pela Lei de Terras, fez com que grande parte dos patrimônios municipais não fosse efetivamente submetido ao regramento da Lei de Terras, na medida em que os Conselhos Municipais continuaram a poder dispor se suas terras de forma autônoma, como por exemplo, por meio de Carta de Data, que era o mecanismo formal de concessão de áreas para o uso privado (BRITTO, 2006).

Nesse sentido, a obrigatoriedade do registro paroquial estava circunscrito àquelas áreas que não estavam sob o regramento da décima urbana (que, portanto, era a área 
considerada como urbana). Contudo, a lei provincial supracitada destaca que a décima urbana não era aplicada na Câmara da Capital, o que infere que todos aqueles que estavam regidos sob a área de Belém deveriam submeter-se ao regramento da Lei de Terras e, portanto, deveriam prestar declarações para fins de confecção do registro paroquial.

Neste sentido, é notável que a obrigatoriedade do registro subsistia a todos (com raras exceções, já estudadas acima), fosse no âmbito urbano, fosse no âmbito rural, na medida em que a desorganização territorial era latente em todos os setores nacionais, tendo sido criada a lei de terras justamente com um desses objetivos. Assim sendo, a aplicabilidade da lei de terras era essencial para que houvesse a organização dos perímetros urbanos.

\section{APLICAÇÃO DA LEI DE TERRAS NO MUNICÍPIO DE BELÉM: UMA ANÁLISE A PARTIR DOS REGISTROS PAROQUIAIS DE BENFICA}

Benfica é considerada como uma das vilas mais antigas do estado do Pará (fundada em 1654), sendo, à época da edição da Lei de Terras, era considerada uma circunscrição da capital (MUNIZ, 1916) ${ }^{4}$, sendo uma vila de ex-escravos que posteriormente seria transformada em uma colônia agrícola ${ }^{5}$. A Freguesia de Benfica foi criada em 1758 como sendo uma vila pertencente à capital, e foi anexada à colônia de Benevides em 1880, por meio da lei $\mathrm{n}^{\circ} 967$, de 15 de novembro do referido ano.

Benfica, assim como diversas outras vilas próximas à região da atual Zona Bragantina, teve o seu projeto de colonização direcionado para ser um espaço destinado à produção agrícola em razão da disposição do terreno, os seus recursos naturais e o comércio ali existente e desenvolvido. Se comunicava diretamente com a capital por meio do porto, onde havia não apenas o deslocamento de pessoas, mas também de mercadorias (NUNES, 2008).

O livro de Benfica foi aberto em 16 de julho de 1854, pelo Vigário José Joaquim, tendo sido finalizado em 23 de agosto de 1917, composto no fim por 187 declarações de posse $^{6}$.

Com base nas informações extraídas do livro em questão, foi possível verificar a existência de 125 descrições legíveis, com a menção de quem era o declarante; a descrição

\footnotetext{
${ }^{4}$ Atualmente Benfica é um distrito do município de Benevides.

${ }^{5}$ Fonte: IBGE

${ }^{6} \mathrm{O}$ livro analisado encontra-se sob a guarda no Instituto de Terras do Pará - ITERPA, junto com os livros das outras Freguesias (Sé, Santíssima Trindade e Sant'Anna), além de todas as demais documentações que fazem parte do acervo do patrimônio público e privado do estado do Pará.
} 
das áreas; as formas e datas de aquisições; a indicação se era localizado no perímetro urbano ou rural; algumas outras informações importantes (tal como se a declaração foi feita mediante procurador ou se o declarante era analfabeto); e por fim, a correspondência atual das áreas na cidade de Belém, mediante o uso do livro de Cruz (1992).

A análise quantitativa dos dados foi baseada nas declarações que se encontravam legíveis (existem 13 registros ilegíveis e 49 inexistentes) e que foram devidamente transcritas e digitadas. Foram levantados os seguintes pontos: a relação entre os imóveis considerados como urbanos e os considerados como rurais; as formas de aquisição das áreas declaradas; e a relação dos que declararam pagar foro à Câmara Municipal de Belém.

No que se refere à classificação urbano/rural, foi possível identificar a partir das descrições que época todas as áreas descritas e registradas na Freguesia de Benfica eram consideradas rurais, o que resultou em $100 \%$ das áreas no perímetro considerado como rural à época, o que se justifica em razão do contexto econômico que a Freguesia estava inserida, como sendo uma colônia agrícola.

Quanto à forma de aquisição das áreas declaradas, a maior parte das declarações sequer mencionavam qual era a origem da área que estavam registrando, culminando num total de 33 (trinta e três) registros nesta situação, relativos a aproximadamente $26,4 \%$ do total. No entanto, existem registros que o declarante referia qual era a origem da área. Destes, 31 (trinta e um) afirmaram que a propriedade era advinda de compra e venda, resultando em aproximadamente $24,8 \%$ do total. Outra origem declarada era de herança, relativos a 24 (vinte e quatro) registros, no total de aproximadamente 19,2\% das declarações, mesma quantidade de registros que declararam que era terra pública. Existiam ainda aqueles que declararam que a área era oriunda de algum tipo de justo título (mas sem mencionar qual), com 09 (nove) registros, resultando em 7,2\%; declarações vindas de algum tipo de doação, existindo 02 (dois) registros, o que representa 1,6\%; e aforamento e concessão, com 01 (um) registro de cada espécie, relativos a aproximadamente $0,8 \%$ cada um.

No que se refere ao pagamento de foros à Câmara de Belém, dos 125 registros legíveis e que foram analisados, apenas 10 (dez) declararam que pagavam foros, o que representa $8 \%$ de todas as declarações.

Foi possível constatar ainda que parte das declarações mencionavam que possuíam escritura pública, o que representou 11,2\% das declarações (14 registros), o que é um dado interessante. Entretanto, o ponto mais interessante da análise quantitativa é em 
relação a quantidade de anotações nos livros das posses que foram legitimadas, o que representou apenas $0,8 \%$, que foi um único registro.

Tento em vista a imprecisão das declarações, no tocante às suas localizações, foi possível aferir apenas que se tratavam todas de áreas consideradas como rurais, sem ser possível verificar as localizações (precisas ou aproximadas).

Além disso, foi possível verificar existência de declarações em que constava que o possuidor pagava foro à Câmara Municipal, um mecanismo de exploração patrimonial bastante comum à época, como já explanado outrora, indicando, assim, que a propriedade era do Município de Belém, sendo, portanto, considerado como patrimônio público. É possível, portanto, aferir a continuidade do sistema aforamento como mecanismo de controle da propriedade privada (MADUREIRA, 2012).

Entretanto, como a maioria dos registros não indicavam qual era a origem da área que estavam registrando, não é possível aferir, com precisão, de que apenas estes 10 registros, dos 125 que foram analisados, eram os que de fato pagaram foro à Câmara Municipal, na medida em que é grande a quantidade de declarações sem a menção da sua origem, podendo existir, dentre esses registros outros casos de pagamento de foro à Câmara, mas que não foi mencionado em razão do fato de que o valor do pagamento dos emolumentos dos registros paroquiais variavam em razão do número de palavras, existindo diversas casos em que o declarante se mostrava sucinto em razão do preço que poderia pagar pela declaração que estava prestando.

Ainda no que tange às declarações, foi possível verificar que muitos eram os casos em que igarapés ou rios eram considerados como limites para os seus terrenos, ratificando um fato já discutido neste trabalho, qual seja a grande quantidade de casos em que havia a imprecisão das localizações das áreas, fosse no perímetro urbano, como aqui constatado, fosse em perímetros rurais.

Entretanto, apesar da ausência de grandes detalhes, foi possível constatar dentro das declarações que mencionavam a origem, grande parte relatava que o seu terreno era oriundo de compra e venda, representando 33,6\% destas declarações, tendo sido aferidos 31 (trinta e um) registros nessa situação dentre os 92 analisados que havia menção de possível origem. 


\section{CONCLUSÃO}

A edição de uma lei regulamentadora do acesso à propriedade se fazia necessário até mesmo para o próprio desenvolvimento do Estado, na medida em que foi apenas com o advento da Lei de Terras que foi possível se falar na criação de propriedade privada de fato (antes se tinha propriedade do estado e semi-estatal), bem como na democratização do acesso, na medida em que uma das suas finalidades (tal como previa o decreto paraense $n^{\circ} 410$ ) era que houvesse o fomento das pequenas propriedades em detrimento à expansão do latifúndio, que era uma característica marcante do regime sesmarial e do regime senhorial.

Além disso, ainda que registro paroquial não fosse considerado como um documento hábil para comprovar o domínio da propriedade, na medida em que se tratava de meras declarações, o mesmo poderia ser usado como mecanismo de prova relativo à posse para requerer, posteriormente, a legitimação da mesma e a consequente expedição de título de domínio.

A forma que os municípios brasileiros foram criados fez-se necessária a aplicação de uma regulamentação, qual fosse, e lei $\mathrm{n}^{\circ} 601$ e o decreto $\mathrm{n}^{\circ} 1.318$ de 1854 em razão da existência de diversos problemas fundiários, tal como a inexistência de delimitações concretas das áreas que eram cedidas, ou até mesmo a existência de casos em que o município de Belém havia doado porções de terras sem que tivesse competência para isso.

Nesta perspectiva, considerando ainda que o problema inicial a ser respondido com o presente artigo era qual seria a origem fundiária da cidade de Belém relatada por meio das declarações formuladas pelos seus próprios habitantes à época da manutenção do livro da Freguesia de Benfica, e se seria possível identificar a atual correspondência destes registros na atual configuração urbana da cidade.

Foi possível concluir que não se tem como afirmar qual a origem da estrutura fundiária de Belém, não sendo possível também construir apenas a correspondência atual dos registros em um para atualizado da cidade de Belém, em razão da imprecisão das delimitações mencionadas em todos os registros, como outrora citado.

Não obstante, ainda se faz necessária a complementação da pesquisa para se verificar se essa mesma situação se repete nas áreas abrangidas pelas demais freguesias (Sé, 
Trindade $)^{7}$, para saber ainda se é possível afirmar qual a origem da estrutura fundiária de Belém.

\section{REFERÊNCIAS BIBLIOGRÁFICAS}

ALMEIDA, Candido Mendes de. Codigo Philippino, ou, Ordenações e leis do Reino de Portugal : recopiladas por mandado d'El-Rey D. Philippe I. Rio de Janeiro : Typ. do Instituto Philomathico, 1870. Disponível em: <http://www2.senado.leg.br/bdsf/item/id/242733>. Acesso em 12 dez 2015.

AMBROZIO, Júlio César Gabrich. O território da enfiteuse e a cidade de Petrópolis-RJ, Brasil. Scripta Nova: revista electrónica de geografía y ciencias sociales, v. 16, 2012.

ARAUJO, Ionnara Vieira de. Regularização fundiária e terras devolutas. Revista da Faculdade de Direito da UFG, [S.1.], v. 33, n. 2, p. 112/127, mai. 2010. ISSN 0101-7187. Disponível em: <http://h200137217135.ufg.br/index.php/revfd/article/view/9861/6737>. Acesso em: 05 de dezembro de 2015.

ARAÚJO, Ionnara Vieira de; TÁRREGA, Maria Cristina Vidotte Blanco. Apropriação de terras no Brasil e o instituto das terras devolutas. Revista da Faculdade de Direito da UERJ, n. $19, \quad 2011 . \quad$ Disponível em: <http://www.epublicacoes.uerj.br/index.php/rfduerj/article/view/1716/1330>. Acesso em 16 jan 2016.

ARAÚJO, Renata Malcher. Cidades da Amazônia no Século XVIII: Belém, Macapá e Magazão. 2a Ed. Porto: FAUP, 1998.

BENATTI, José Heder. Direito de propriedade e proteção ambiental no Brasil: apropriação e uso dos recursos naturais no imóvel rural. Belém: Tese de Doutorado, 2003.

BRASIL. Colecção das Decisões do Governo no Império do Brazil de 1821. Rio de Janeiro: Imprensa Nacional, 1889.

Colecção das Decisões do Governo no Império do Brazil de 1822. Rio de Janeiro: Imprensa Nacional, 1887.

Chttp://www2.senado.leg.br/bdsf/bitstream/handle/id/137569/Constituicoes_Brasileiras_v1_1
824.pdf?sequence=5>. Acesso em 04 jan 2016.
1849.

Coleção das leis do Império do Brasil de 1848. Rio de Janeiro: Typografia Nacional,

Lei 601 de 18 de Setembro de 1850 - Dispõe sobre as terras devolutas do Império. Disponível em: <http://www.planalto.gov.br/ccivil_03/LEIS/L0601-1850.htm>. Acesso em 06 jan 2016.

\footnotetext{
${ }^{7}$ A pesquisa sobre a Freguesia de Sant'Anna da Campina encontra-se publicada no trabalho de Oliveira; Fischer (2016).
} 
setembro

Decreto $n^{\circ} 1.318$ de 30 de janeiro de 1854 - Manda executar a lei $n^{\circ} 601$ de 18 de <http://legis.senado.gov.br/legislacao/ListaTextoIntegral.action?id=75492\&norma=102306>. Acesso em 06 jan 2016.

Decreto $\mathrm{n}^{\mathrm{o}} \mathbf{5 . 6 5 5}$ de 3 de junho de 1874. Disponível em: <http://www.camara.gov.br/internet/infdoc/conteudo/colecoes/legislacao/legimpcd06/leis1874-v1e2/pdf75.pdf\#page=1>. Acesso em 06 jun 2016.

Coleção das Decisões do Governo do Império do Brasil de 1851. Rio de Janeiro: Typografia Nacional, 1852.

Coleção das Decisões do Governo do Império do Brasil de 1863. Rio de Janeiro: Typografia Nacional, 1864.

BRITO, Mônica Silveira. Modernização e Tradição: Urbanização, Propriedade da Terra e Crédito Hipotecário em São Paulo na segunda Metade do Século XIX. Tese de doutoramento orientada por Margarida Maria de Andrade. São Paulo: Universidade de São Paulo, 2006.

CARVALHO, José Murilo de. Modernização frustrada: a política de terras do Império. Revista Brasileira de História, n.o 1, 1981, pp. 39-57.

CHRISTILLINO, Cristiano Luís. A Lei de Terras e a transição ao capitalismo no Brasil no XIX: uma análise micro dos efeitos da Lei sobre a afirmação da propriedade. Rio de Janeiro: Anais do XII Encontro Regional de História - Usos do Passado, 2006, pp. 1-7. Disponível em:

<http://www.rj.anpuh.org/resources/rj/Anais/2006/conferencias/Cristiano\%20Luis\%20Christi llino.pdf $>$. Acesso em 15 jan 2016.

COSTA, Célio Juvenal; CRUBELATI, Ariele Mazoti; LEMES, Amanda Barbosa; MONTAGNOLI, Gilmar Alves. História do Direito Português no período das Ordenações Reais. Congresso Internacional de História. Vol. 20. No. 07. 2011. Disponível em: <http://www. cih. uem. br/anais/2011/trabalhos/153.pdf>. Acesso em $28 \mathrm{dez} 2015$.

CRUZ, Ernesto. Ruas de Belém: Significado histórico de suas denominações. Belém: Edições Cejup, 1992.

FERREIRA, Eliana Ramos. Em cumprimento ao edital do reverendo vigário: os registros paroquiais no Pará - 1854-1860 (conflitos e tensões). Belém: Revista de História Econômica \& Economia Regional Aplicada - Vol. 7 N 13, 2012.

FREITAS, Augusto Teixeira de. Terras e Colonisação. Rio de Janeiro: B. L. Garnier, 1882.

FRIDMAN, Fania; RAMOS, Carlos Alexandre F. A história da propriedade da terra no Brasil. Anais: Seminário de História da Cidade e do Urbanismo, v. 2, n. 1, 2012, p. 187195.

LACERDA. Manoel Linhares de. Tratados das Terras do Brasil. Volume II. Editora Alba Limitada: Rio de Janeiro, 1960. 
MADUREIRA, Nuno Luís. História do Trabalho e das Ocupações. Oeiras: Celta Editora, 2002.

MARCÍLIO, Maria Luíza. Os registros paroquiais e a História do Brasil. Revista Varia História, $\quad$ v. $31, \quad$ p. $13-20$ 2004. Disponível em: <http://members.tripod.com/historia_demografica/bhds/bhd36/mlm.pdf >. Acesso em 16 de janeiro de 2016.

MARX, Murillo. Cidade no Brasil: Terra de Quem?. São Paulo: Nobel, 1991.

MATTOS NETO, Antônio José. A questão agrária no Brasil: aspecto sócio-jurídico. Revista do Programa de Estudos Pós-Graduados de História, v. 33, n. 1, 2009.

MOTTA, Marcia Maria Menendes. The Sesmarias In Brazil: colonial Land Policies In The Late Eighteenth-Century. E-journal of Portuguese History, v. 3, n. 2, p. 2, 2005.

MUNIZ, João de Palma. Patrimônio dos Conselhos Municipais do Estado do Pará. Belém: Aulliard \& C., 1904.

Limites Municipais do Pará. Belém: Arquivo Público do Pará, 1916.

NOZOE, Nelson. Sesmarias e apossamento de terras no Brasil colônia. Revista EconomiA, v. 7, n. 3, p. 587-605, 2006.

NUNES, Francivaldo Alves. A semente da colonização: um estudo sobre a Colônia Agrícola Benevides (Pará, 1870-1889). 2008. 228 f. Dissertação (Mestrado) - Universidade Federal do Pará, Instituto de Filosofia e Ciências Humanas, Belém, 2008.

OLIVEIRA, Natalia Altieri Santos de; FISCHER, Luly Rodrigues da Cunha. Efeitos da Lei de Terras nas Relações Socioespaciais na Amazônia. Revista Brasileira de História do Direito, v. 2, n. 2, p. 19-38, 2017.

PORTO, Costa. O sistema sesmarial no Brasil. Brasília: Editora da Universidade de Brasília: 1979.

ROCHA, Ibraim; TRECCANI, Girolomo Domenico; BENATTI, José Heder; HABER, Lilian Mendes; CHAVES, Rogério Arthur Friza. Manual de Direito Agrário Constitucional: lições de direito agroambiental. Belo Horizonte: Forúm, 2010.

TRECCANI, Girolomo Domenico. Violência e Grilagem: Instrumentos de Aquisição da Propriedade da Terra no Pará. Belém: UFPA, ITERPA, 2011.

O Título de posse e a legitimação de posse como formas de aquisição da propriedade.

Belém: Procuradoria Geral do Estado do Pará, n. 20, p. 121-158, 2009. 